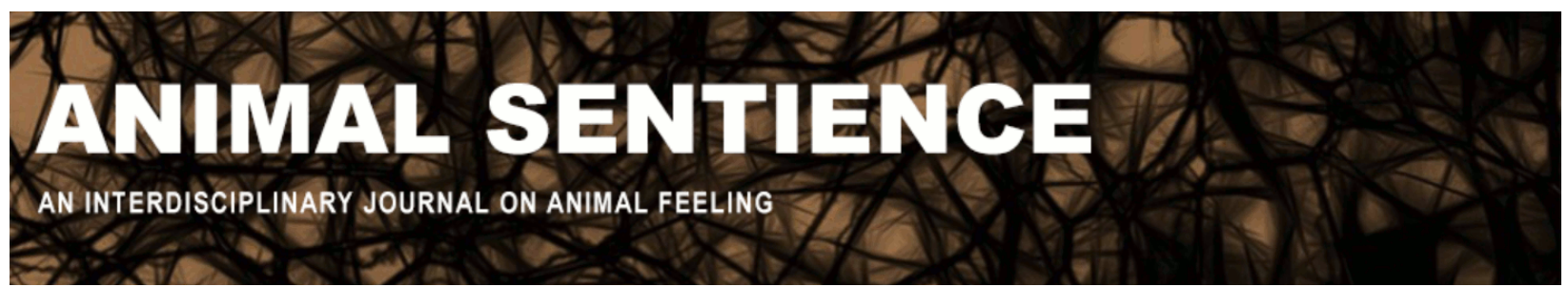

Andrews, Kristin (2018) Chicken minds and moral standing. Animal Sentience 17(14)

DOI: $10.51291 / 2377-7478.1367$

Date of submission: 2018-09-02

Date of acceptance: 2018-09-14 (c) 


\title{
Chicken minds and moral standing
}

Commentary on Marino on Thinking Chickens

\author{
Kristin Andrews \\ Department of Philosophy and Cognitive Science Program \\ York University, Canada
}

\begin{abstract}
Some of the cognitive traits that Marino reviews are not in themselves relevant to ethics, either for chickens or human infants, but affective traits are, among them desires.
\end{abstract}

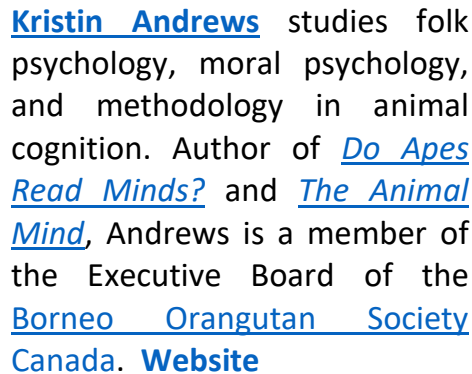

Canada. Website

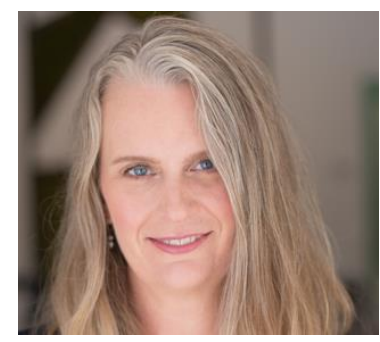

Marino's $(2017 a, b)$ review of what we know about the perceptual, affective, and cognitive capacities of the domestic chicken is presented with an ethical goal in mind: to change what she perceives as our current immoral treatment of chickens. Although the moral argument is merely implicit, Marino suggests that chickens, like humans, have moral standing; that is, they are the sort of thing one must consider when making moral decisions. The implicit argument goes something like this:

1. Humans have moral standing because of our specific perceptual, affective, and cognitive capacities.

2. Chickens have these capacities, at least to some extent.

3. Therefore, chickens also have moral standing.

Both premises of this argument have flaws. In order to see what a stronger argument for chicken moral standing would look like, let's examine the two premises. In premise (1), the claim that perceptual capacities are relevant for moral standing has no precedent in any of our moral theories, and one would be hard-pressed to develop a plausible theory in which perceptual capacities had intrinsic moral value. Cognition is arguably relevant for moral standing, but it is widely thought that there is a boundary between perception and cognition such that the two are distinct sets of faculties. This distinction plays an important role in current vision science. Cognitive capacities are morally relevant on the basis of deontological moral theories (e.g., Immanuel Kant's Critique of Practical Reasoning), and affective capacities are morally relevant on sentimentalist (e.g., David Hume's Enquiry Concerning the Principles of Morals) and utilitarian 
(e.g., John Stewart Mill's Utilitarianism) moral theories. Thus, we can modify premise (1) to read as follows:

1. Humans have moral standing given our affective and cognitive capacities.

With this modification, the section titled "Visual Cognition" is largely irrelevant for drawing the moral conclusion, although the observation that chickens prefer biological motion in point light stimuli does suggest that sociality is salient for the species.

Premise (2) is overstated, implying that chickens have the morally relevant cognitive and affective capacities that humans tend to have. Yet it need not be overstated to draw a moral conclusion. Some of the cognitive capacities discussed are not clearly morally relevant. Other cognitive capacities are ascribed to chickens without sufficient evidence. Marino is right that more research on chickens is needed; we need more evidence in order to draw conclusions about some of the morally relevant properties. But we also need to be clear on what these capacities are; so more theoretical work is also needed. I have discussed most of these cognitive capacities in detail in The Animal Mind (Andrews 2012); below I will briefly examine the current state of the supporting evidence, given my understanding of each capacity.

The cognitive capacities of transitive inference and numerosity are not among those that are taken to be relevant for moral standing. Models of transitive reasoning in animals based on associative processes show how both human and nonhuman animals may be able to perform the sorts of transitive inference tasks given to species from fish to apes (De Lillio et al. 2001). Numerosity abilities like the ones discussed are found in human infants as well as in many nonhuman species, and they are widely considered to be based on a core cognitive process that remains in place for humans who begin to acquire counting and numerical abilities. The ability to keep track of five balls does not imply the existence of "a 'mental number line' indicative of ordinality" (Carey 2009, p. 131). Rather, such abilities can be explained in terms of a different kind of mental state: analog magnitudes (Beck 2012). The transitive inference and numerosity capacities of nonhuman animals are cognitive, but there is no evidence that they are conceptual; and they do not reflect the kind of cognition of interest to deontological, sentimentalist, or utilitarian moral theorists.

Self-control is a more promising capacity of interest for the deontological ethicist. Someone with true self control is able to make judgments of relative value and to refrain from automatic action in order to do the better thing. Does current research indicate that hens have this kind of self-control? The study cited indicates that hens will choose a 4-second longer delay for a much larger food reward. However, with a closer look at the study, it is apparent that the hens, who were food deprived, then trained and tested in an operant apparatus, learned to associate the larger reward with the relevant stimuli; in a forced-choice task, hens chose the larger reward, as would be expected. Time and food rewards are both salient variables, but the difference between the time delays is a fraction of the difference between the size of the food rewards. Self-control in apes is tested quite differently. Like the marshmallow task given to children, in which children are left alone with a marshmallow and told that they can eat it now, or wait, and eat two later, apes have to avoid eating the food in front of them to gain a larger reward later. Human children and apes alike will sometimes distract themselves from the tasty 
treat in order to help them control their desire to eat it now. Nothing like that is apparent in the hen study.

Perspective-taking is a cognitive capacity that is also discussed in the context of moral status. Understanding what another sees, feels, wants, or believes is a key capacity for moral agency. It is less clear whether it is needed for mere moral standing. Human children only develop this capacity slowly, yet they are held to merit moral consideration long before they can engage in perspective-taking. This is a good thing for Marino's goals, since the evidence she presents for perspective-taking in chickens fails to take into account the distinction between tactical and intentional deception (Byrne \& Whiten 1988). Tactical deception involves "acts from the normal repertoire of the agent, deployed such that another individual is likely to misinterpret what the acts signify, to the advantage of the agent" (Byrne \& Whiten 1991, p. 127). Intentional deception, on the other hand, requires that the deceiver intends that the other has a false belief. Marino presents as evidence of perspective-taking the observation that subordinate males inhibit the vocal part of the tidbit-eating display when a dominant male is not otherwise distracted. However, given the criteria developed by Byrne \& Whiten, this behavior would be categorized as an instance of tactical deception, which is rife across species, and, like the wing-dragging behavior of the piping plover who lures the predator from her nest, may be an ungeneralizable species-specific behavior. That said, the flexibility of chickens' vocalizations more generally indicates a social awareness that may turn out to be more relevant morally than the capacity for perspective-taking.

Intentional deception requires one form of perspective-taking, empathy requires another. Empathy is usually distinguished from sympathy as requiring knowledge of how another feels, and feeling that same emotion with another person, whereas sympathy is an experience of concern for another. Empathic contagion, on the other hand, is not usually described as requiring perspective-taking capacity: We don't think that infants who start crying because another infant starts crying understand what the other infant is feeling. The study showing that hens' physiology changed when their chicks were given an air puff, even though the air puff wasn't aversive to the hens themselves, suggests to Marino that the hens could put themselves in the "shoes" of the chicks and realize how the air puff would feel to them, even when it didn't feel like much to the hen herself. Hens who didn't experience the air puff first didn't display any heightened physiological response when observing an air puff directed at their chicks. Whereas one possibility is that the hens took the perspective of their chicks, another is that the hens learned about the air puffer (which is vaguely annoying) and their response was the same as it would be in response to any threat toward their chicks.

Although episodic memory is not a capacity traditionally invoked as grounds for according moral standing, it is often invoked as grounds for according the status of "person," and persons have moral standing. Do we currently have evidence that chickens have episodic memory? Endel Tulving (2005), who coined the term, defines it as "The operations of episodic memory require, but go beyond, the semantic memory system.... The essence of episodic memory lies in the conjunction of three concepts - self, autonoetic awareness, and subjective time" (p. 9). Having episodic memory entails self-consciousness, then, and is part of a larger capacity of mental time travel, "sending" ideas of oneself into possible futures and back into the past. Chickens' ability to match-to-sample indicates semantic memory, but it offers no evidence for mental time travel in the way Tulving describes. 
Whereas there is currently no compelling evidence of episodic memory, perspectivetaking, sense of self, self-control, deductive reasoning, or true numerical ability in chickens, there is evidence of memory, prediction, communication, associative reasoning, and numerosity. The same is true of many humans (e.g., children) who lack the former set but have the latter yet still enjoy moral standing. None of the former set of cognitive capacities is morally irrelevant, but they are not going to be required for moral standing by any moral theory that takes human infants to be eligible for moral standing in their own right.

Affective capacities are more clearly relevant when it comes to arguing for moral standing for organisms like human infants and nonhuman animals. This is of primary import for utilitarian and sentimentalist moral theories. Fortunately for Marino's overarching goal, the current evidence we have for the affective capacities of chickens is more compelling. If we focus on chicken communication (and the relationship between communication and emotional responses to social structures and perhaps even norms), physiological responsiveness to harm directed at oneself and others, variable attention paid to other individuals depending on their role in the community, preferences, emotions, individual differences and personality, we have a more promising set of capacities relevant for moral standing. These capacities suggest that chickens have desires.

Any sentient creatures who can communicate their desires to us thereby make some kind of a moral claim on us. Even if we do not act to fulfill their desires, we take up a moral obligation not to impede their desires without some good reason. As Hume (2010) put it, "Would any man, who is walking along, tread as willingly on another's gouty toes, whom he has no quarrel with, as on the hard flint and pavement?"

The mere fact that chickens cannot communicate their desires to us does not negate the fact that they have them. With continuing research on the content of their desires, we can come to learn what those desires are.

If it is sufficient for moral standing that one values what happens to oneself - that is, that one has goals and corresponding desires to fulfill them - then chickens also have moral standing. The revised, more plausible version of Marino's implicit argument goes like this:

1. Anyone who values what happens to them has moral standing.

2. Chickens value what happens to them.

3. Therefore, chickens have moral standing.

The argument is more plausible than the one we started with, but the premises do require defense. It requires conceptual and theoretical work defending the criteria for moral standing. And it requires empirical research on chickens to determine what they value. Marino has shown us that there is much research that can be done with chickens. And she rightly suggests that we have a moral obligation to learn what they have to teach us. 


\section{References}

Andrews, K. (2015) The Animal Mind: An Introduction to the Philosophy of Animal Cognition. Routledge.

Beck, J. (2012a) The generality constraint and the structure of thought. Mind, 121, 563-600.

Byrne, R., and Whiten, A. (1991). Computation and mindreading gin primate tactical deception. In A. Whiten (Ed.), Natural Theories of Mind: Evolution, Development, and Simulations of Everyday Mindreading. Oxford: Blackwell Publishers.

Carey, S. (2009) The Origins of Concepts. New York: Oxford University Press.

De Lillo, C., Floreano, D., and Antinucci, F. (2001) Transitive choices by a simple, fully connected, back- propagation neural network: Implications for the comparative study of transitive inference. Animal Cognition, 4(1), 61-68.

Hume, D. (2010) The Project Gutenberg EBook of An Enquiry Concerning the Principles of Morals.

Marino, L. (2017a) The inconvenient truth about thinking chickens. Animal Sentience 17(1)

Marino, L. (2017b) Thinking chickens: A review of cognition, emotion, and behavior in the domestic chicken. Animal Cognition, 20, 127-147.

Whiten, A., \& Byrne, R. (1988) Tactical deception in primates. Behavioral and Brain Sciences, 11, 233-273. 